\title{
Pedagogical Competence of the High School Teacher
}

\author{
Anastasiya Viktorovna Fakhrutdinova ${ }^{1}$, Mayya Rashidovna Ziganshina ${ }^{2}$, \\ Veronika Alexandrovna Mendelson ${ }^{3} \&$ Lyubov Grigorevna Chumarova ${ }^{1}$ \\ ${ }^{1}$ Department of foreign languages, Institute of International Relations, Kazan (Volga region) Federal University, \\ Russia \\ 2 Department of light industry and fashion technology, Kazan National Research Technological University, \\ Kremlyovkskaya, Kazan, Russian Federation \\ ${ }^{3}$ Department of Materials and technologies of light industry of Kazan National Research Technological University, \\ Kremlyovkskaya, Kazan, Russian Federation
}

Correspondence: Anastasiya Viktorovna Fakhrutdinova, Department of foreign languages, Institute of International Relations, Kazan (Volga region) Federal University, Russia. E-mail: avfach@ mail.ru

Received: September 3, 2020

Accepted: October 22, 2020

Online Published: October 31, 2020

doi:10.5430/ijhe.v9n8p84

URL: https://doi.org/10.5430/ijhe.v9n8p84

\begin{abstract}
The need conditions the relevance of the article for the formation of higher education teachers' pedagogical competence as the optimal system and purposeful work in this direction has not yet been formed. The goal of the article lies in the analysis of the study of the theoretical aspects of higher education teachers' pedagogical competence and identifying the main types of professional competence. The leading approach to the study of this problem for the authors was their understanding of the concept of "competence", the distinction between the concepts of "qualification" and "competence", as well as an understanding of the essence of higher school teacher's pedagogical competence. The article presents a scheme of competencies of a higher school teacher, a distinction between key, subject and professional competencies. Taking into account the results of this study, it is possible to identify several scientific problems and promising areas that require further consideration: in particular, the development of new training programs for teachers of higher education institutions.
\end{abstract}

Keywords: education, high school, professional-pedagogical competence, pedagogical competence, competence, higher education

\section{Introduction}

Undoubtedly, in today's fast-paced world, the significance of Professional and pedagogical competence in enhancing education quality is beyond question. In modern, rapidly changing socio-economic conditions, when numerous information flows are being integrated and operational knowledge gets old rapidly the problem of training University teachers able to conduct multi-functional activities associated with higher education and work in a perpetual mode of innovative development is particularly acute. Nowadays, there is a demand for a special kind of teacher, the teacher capable of executing the social and professional impact of education and form, first of all, the personality of a new century, capable of creativity, self-realization. In this situation, of particular importance is the problem of pedagogical competence formation of the higher education teacher, designed to develop not only professionalism but also the outlook of the future specialist - the intellectual and creative elite of society, possessing sustainable knowledge and skills, ready for creative and innovative work.

\subsection{The Relevance of the Topic}

The connection of the topic being researched is adapted by the fact that the issue of pedagogical competence of the of higher education teacher every year gains growing significance associated with the global changes in the economic, social, socio-cultural situation in the country. Now, even demanded higher educational institutions are entered by the students not sufficiently involved in the learning process and not aware of its meaning, who do not set 
themselves the purpose of mastering a particular profession. Teachers perceive a dynamic decline in the level of students' learning culture, inability to learn and organize their educational growth, unwillingness to learn.

As can be observed, the relevance of the topic being investigated is based on the three main aspects:

Firstly there is a social order for a higher education teacher, who has a relatively broad professional competence, the main component of which, of course, is high pedagogical competence, as the primary education goal is the transformation of the initial state, the expansion of the zone - knowledge, cognitive horizons, development and assignment of knowledge through a particular system of skills;

Secondly, the investigation of modern teaching practice state in universities (both state and non-state, with budget or commercial funding) also supports the need for the higher education teachers' pedagogical competence formation, because the optimal system and purposeful work in this direction (in comparison with the training, for example, teachers in the system of pedagogical universities) has not yet been formed.

Finally, the training of higher school teachers in terms of their pedagogical competence is often, unfortunately, not perceived as a severe problem in most cases by those who are directly concerned — the higher education teachers themselves. Some even believe that there is no subject for discussion: for successful students' training, the teacher should be good enough at his subject, and the rest will come with experience (Sopin \& Varkovetskaya, 2013; Byhar et al., 2020 ).

According to statistics, the proportion of teachers who do not have basic pedagogical education increases quite significantly at the level of higher education (up to $73 \%$ ) compared to secondary vocational (45\%) or General education (about $10 \%$ ) (Dneprov et al., 2017). This situation is because special pedagogical training is not a necessary condition or criterion for implementation of teaching or certification, and practically it does not affect the personal rating in contrast to the scientific work of the teacher. According to Part 1 of Art. 46 of the Federal law of 29.12.2012 № 273-FZ “On Education in the Russian Federation” “...people with secondary vocational or higher education meeting the qualification requirements specified in the qualification guides, and (or) professional standards have the right to be engaged in educational activities”. (Federal Law № 273-FZ, 2012). Training for additional professional programs on the profile of pedagogical activity is recommended at least once every three years. Thus, the Law does not prescribe the teacher's pedagogical education as obligatory.

\section{Literature Review}

Researchers started talking about professional competence as a pedagogical problem relatively recently — only in the 90s of the twentieth century. However, the issue itself has long been featured, yet, directly and indirectly, both in domestic and foreign scientific theories.

First of all, it should be noted that the concept of "pedagogical competence" has recently gained its priority position in the system of basic pedagogical categories. At the same time, the semantic boundaries of such concepts as "qualification", "competence" and "competent" have not yet been defined and differentiated sufficiently. Moreover, in the Russian language, the first two phenomena are called компетенция and компетентность, which both are traditionally translated into English by the same word "competence". That is why in this article we fall down to two different terms: qualification - an ability, characteristic, or experience that makes you suitable for a particular job or activity (Cambridge Dictionary) and competence - the ability to do something well (Cambridge Dictionary).

The definitional analysis shows that "qualification" is semantically primary category, and "competence" is derived from its concept, denoting the sphere of application of knowledge, abilities and skills of the person, while "qualification" represents their interiorized essence, i.e. assigned in personal experience set, system, a specific knowledge "baggage" of the professional.

Scientific analysis of this concept's definitions showed that pedagogical competence is defined as "an integral manifestation of the qualities of the teacher's personality, which combines elements of professional and general culture, experience, the experience of pedagogical activity and pedagogical creativity" (Abrosimov, 2001); "integrated vocational and personal characteristics that define the willingness and ability to fulfil pedagogical functions in accordance with specific historical norms, standards and requirements accepted in society, the baseline of which is the attitude of the man" (Grigorieva \& Dumov, 2003; Vovk et al., 2019).

The interpretation of pedagogical competence as the possession of "the necessary amount of knowledge and skills that determine the formation of his pedagogical activity, pedagogical communication and the personality of the teacher as a carrier of certain values, ideals and pedagogical consciousness; a set of knowledge, experience, skills of 
flexible possession of pedagogical technology, finding the optimal means of influence on the student, taking into account his needs and interests, rights and free choice of ways of activity and behaviour" (Kojaspirova \& Kojaspirov, 2005) also seems quite interesting. Consequently, pedagogical competence is a professional and personal characteristic of the teacher, providing a high level of scientific and pedagogical activity.

The composition and structure of pedagogical competence are determined by the features and design of professional activity. The pedagogical activity of a higher educational institution teacher is a multifaceted system. As a rule, it consists of two basic components: pedagogical and research activities. According to the results of the researches being conducted, more than 80 different types of labour are involved in the teacher's professional activity of, forming 5 areas: educational, educational-methodical, research, organizational and methodical work and education of students. Most teachers do not pay due attention to such an important activity field as monitoring and analysis of higher education problems. (Lopanova, 2015).

\section{Results}

Most of the teachers try to avoid contradictions that exist in the educational process, not paying due attention to the causes of this contradictions. This fact can be explained by the insufficient level of pedagogical competence. It is impossible to build an ideal model of competence that forms the competence of the teacher. The teacher's structural model is a tool that should not exist as a rigid system that closes the individuality of a teacher in any framework of requirements.

But the existence of such a tool allows us to implement effective strategic and operational tasks related to the achievement of the necessary quality and efficiency standards, both at the individual and organizational levels.

On the basis of definitions of the "competence" concept, we suggest as pedagogical competence the system of skills acquired, as a result of some studied discipline; ability to carry out specific activities based on acquired habits, skills and knowledge. That is the established requirement for the professional training of a student.

A set of competencies forms a pedagogical competence. We came to distinguish between five basic types of professional competence:

1. special competence in the field of the taught academic discipline;

2. methodological competence in the sphere of the students' knowledge and skills formation ways;

3. socio-psychological competence in the field of pedagogical communication;

4. differential-psychological competence in the field of students' abilities to assimilate knowledge;

5. autopsychological competence in the field of advantages and disadvantages of the teacher's activity and personality.

On the basis of the most significant goals of education, the structure of existing experience, the basic types of the learner's activity, allowing him/her to master social experience, identify several basic competences in pedagogy (Krylova \& Dautova, 2016), which together form the competence of a higher education teacher:

1. Value-semantic competencies. Here belong value orientations, factors of self-determination and self-realization, features of the world outlook;

2. General cultural competencies, including human activity experience in the field of national culture; spiritual and moral guidelines of a person; culturological preconditions of social phenomena, family traditions; the level of science and religion importance; competence in the cultural and leisure sphere;

3. Educational and cognitive competences contain details of logical, methodological activity; goal and tasks setting; planning, monitoring, analysis; ways of solving educational and cognitive tasks;

4. Informational competence involves the collection, study, analysis and identification of necessary information, its preservation and transmission; possession of information technologies;

5. Communicative competences. These include the mastery of languages, communication techniques, ability to manage conflicts;

6. Socio-labor competence assumes the role of citizen, producer, consumer, client, observer, etc;

7. Personal self-improvement competences. They include the ability to self-development; ecological culture. 
Having analyzed the basic competences in pedagogy and the most significant goals of education, we came to develop the scheme of the pedagogical competence's general structure (Figure 1).

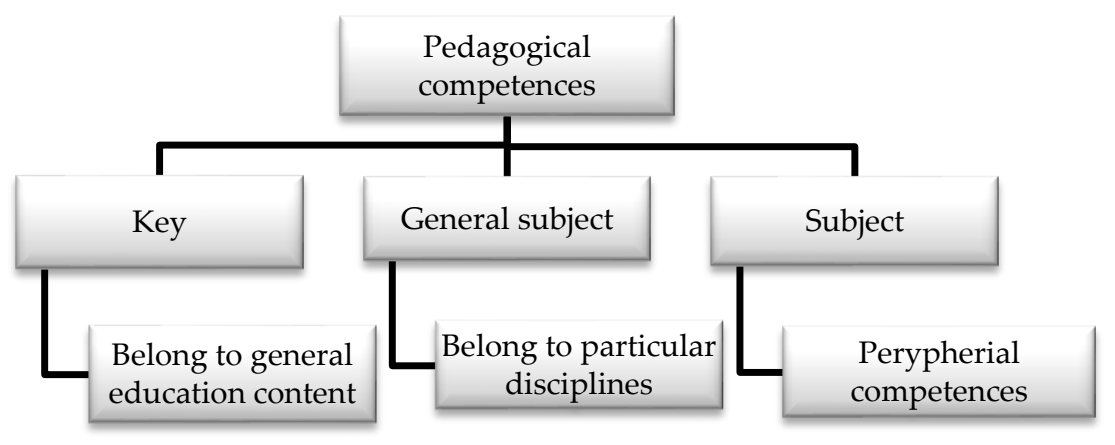

Figure 1. General structure of the higher school teacher pedagogical competence

Key competencies belong to the general content of education; general subject pedagogical competences refer to a specific range of educational subjects and educational areas; subject competencies are the private components of the two previous competencies. Discipline competencies have a precise description and are formed within the framework of any academic disciplines.

Due to the fact that the teacher's pedagogical competence contains the system of social requirements for the university teacher as a professional, let us turn to the State requirements for the minimum level and content of training to be qualified as a "High School Teacher", approved by the Ministry of Education of the State.

The program is designed to prepare master students, post-graduate students (adjuncts), as well as specialists with higher education and at least 2 years of work experience for pedagogical activity at a higher educational institution (Order № 180, 2002).

Qualification "Higher Education Teacher" is certified by the "Diploma additional (to higher) education", and is additional to the basic qualification received by a magistracy graduate. (Order № 180, 2002).

The aim of the program is to prepare the future higher education teacher for educational and research activities. A high school teacher should know:

- the basis of psychology; the specifics and difficulties of teaching and upbringing in higher education; the biological and psychological boundaries of information perception and assimilation; the psychology of youth; the influence of the students' individual characteristics on the final result of their pedagogical activity;

- the main features and trends of higher education pedagogy, innovative approaches to the organization of pedagogical activity;

- legal and regulatory framework of the educational system;

- economic features of the education system functioning.

\section{Discussion}

The previous researches, which were made by Y. K. Babansky (1989), I. B. Kotova (2008), E. I. Rogov (2000), E. L. Fedotova (2019), E. N. Shiyanov (1999) were devoted to the pedagogical competence of a teacher as the basis teachers - students interaction: some researchers talk about pedagogical interaction, others - on educational interaction N. M. Borytko (2001), I. A. Kolesnikova (2005), E. M. Safronova (2011), the third - about dialogical interaction (M. S. Baimatova (2017), V. Mendelson \& M. Ziganshina (2013), A. V. Fakhrutdinova (2016). Despite the differences in names, we can distinguish a common starting point - the process of such interaction is based on humanistic principles. 
Nevertheless, the amount of researches devoted to the high school teacher's pedagogical competence is quite limited and they have a discussion character.

\section{Conclusions}

Consequently, a meaningful analysis of the components of the high school teacher pedagogical competence makes it possible to assert that it assumes the knowledge of the taught subject; creative organization of training on the basis of increasing intensity, individualization and independent creative work, development of students' creative potential.

A high school teacher should be able to:

- apply in the educational process the knowledge of historical basis, modern developments, modernization trends in the scientific field, its integration with other sciences;

- present the teaching material in direct connection with the disciplines in the curriculum;

- use the knowledge of culture and art as a means of students' education.

\section{Acknowledgements}

The work is performed according to the Russian Government Program of Competitive Growth of Kazan Federal University.

\section{References}

Babansky, Y. K. (1989). Selected Pedagogical Issues. Moscow: Pedagogics.

Baimatova, M. S. (2017). Educational and methodical manual on preparation for competitions of professional skill of workers of education. Volgograd.

Borytko, N. M. (2001). In the Space of Educational Activities. Volgograd: Peremena.

Byhar, H. P., Zvozdetska, V. H., Prokop, I. S., Pits, I. I., \& Hordiichuk, O. Y. (2020). Pedagogical Conditions for the Development of Self-Educational Competence of Future Specialists in the Study of Professional Subjects. International Journal of Higher Education, 9(7).

Dneprov, S. A., Sumina, T. G., \& Venkov, S. S. (2017). Objectivity of Experts' Assessment of the Study of Secondary Vocational School Teacher's Readiness to Teaching. Pedagogical Statistics, (53-60).

Fakhrutdinova, A. V., \& Kondrateva, I. G. (2016). Contemporary tendencies of social tutoring in period of multiculturalism: moral characteristic. Man in India, 96(3), 853-858.

Fedotova, E. L. (2019). Informational Technologies in Science and Education. Moscow: Forum.

Kolesnikova, I. A. (2005). Pedagogical Projecting. Moscow: Academia.

Kotova, I. B. (2008). General Psycology. Rostov on Don. Academic Centre.

Krylova, O. N., \& Dautova, O. P. (2016). "Profile of competences" of a Teacher of Higher Education as an Instrument of his Professional Development. Pedagogy Publishing House: St. Petersburg, 3(105-110).

Lopanova, E. V. (2015). Professional-pedagogical Competence of the University Teacher: Structure, Content, Assessment of the Formation. Scientific review. Pedagogical sciences, 2(121).

Mendelson, V. A., \& Ziganshina, M. R. (2016). Intercultural Communication in Professional Education. Kazan, KNTRU Publishing house.

Mendelson, V. A., Ziganshina, M. R., \& Plastinina, S. V. (2013). The Ways to Adapt Technical University Students to Their Professional Activities by Means of Foreign Language. Proceedings of the International conference International Conference on Interactive Collaborative Learning (ICL), p. 152-155. Kazan: KNTRU.

Order issued on January 24, 2002, N 180. On the Implementation of the State Requirements to the Minimum Content and Level of Training for Obtaining Additional Qualification "Teacher of Higher Education"

Safronova, E. M. (2011). Conditions for the Effectiveness of the Educational Process in Higher Education. Volgograd.

Shiyanov, E. N., \& I. B. Kotova. (1999). Personality Development in Education. Moscow: Academia. 
Sukhaeva, A. R., \& Ivanova, S. V. (2010). Problems of the Quality of Professional Training of a Specialist. Modern High Technology, 7(283-285).

Vovk, M. P., Sotska, H. I., Trynus, O. V., \& Muzyka, O. J. (2019). Assessment of Instructors' Technology Competency to be Used in the Settings of Formal and Non-Formal Education. International Journal of Higher Education, 8(5), 4-12.

\section{Copyrights}

Copyright for this article is retained by the author(s), with first publication rights granted to the journal.

This is an open-access article distributed under the terms and conditions of the Creative Commons Attribution license (http://creativecommons.org/licenses/by/4.0/). 